\title{
MULTILAYERED NARRATION IN ELECTROACOUSTIC MUSIC COMPOSITION USING NUCLEAR MAGNETIC RESONANCE DATA SONIFICATION AND ACOUSMATIC STORYTELLING
}

\author{
Falk Morawitz \\ University of Manchester, \\ Oxford Road, \\ Manchester, M13 9PL, United Kingdom \\ falk.morawitz@manchester.ac.uk
}

\begin{abstract}
Nuclear magnetic resonance (NMR) spectroscopy is an analytical tool to determine the structure of chemical compounds. Unlike other spectroscopic methods, signals recorded using NMR spectrometers are frequently in a range of zero to $20000 \mathrm{~Hz}$, making direct playback possible. As each type of molecule has, based on its structural features, distinct and predictable features in its NMR spectra, NMR data sonification can be used to create auditory 'fingerprints' of molecules. This paper describes the methodology of NMR data sonification of the nuclei nitrogen, phosphorous, and oxygen and analyses the sonification products of DNA and protein NMR data. The paper introduces On the Extinction of a Species, an acousmatic music composition combining NMR data sonification and voice narration. Ideas developed in electroacoustic composition, such as acousmatic storytelling and sound-based narration are presented and investigated for their use in sonification-based creative works.
\end{abstract}

\section{INTRODUCTION}

Spectroscopy is a field of research that analyses the interactions of electromagnetic waves and physical matter [1] It is used to examine the molecular structure, bonding strengths, energy level distribution, compound weight, and many other factors of chemical compounds. Sonification of spectroscopic data has been used in scientific research to determine quantum coupling in oscillating atoms [2] or to perceptualize the properties of subatomic particles [3]. In a musical context, infra-red spectroscopy data have been used to create microtonal musical scales [4] and have been sonified for the exploration of new sonorities [5][6].

The focus of this paper is the sonification of NMR data, with sections 1.1 and 1.2 detailing the basis of NMR spectroscopy and the use of NMR data sonification in science and art, respectively. The second part of the paper is concerned with the presentation and the aesthetics of the sounds created. This paper explores the use of narration as key to support sonification and examines strategies developed in acousmatic music compositions, including acousmatic storytelling and sound-texture-based narration for their use in sonificationbased compositions. The acousmatic work On the Extinction of a Species is discussed as a case study in chapter 3.2.

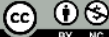

Attribution - Non Commercial 4.0 International License.

The full terms of the License are available at

http://creativecommons.org/licenses/by-nc/4.0/

\subsection{An introduction to NMR spectroscopy}

Nuclear magnetic resonance (NMR) spectroscopy examines the resonance frequencies of magnetic nuclei observable under strong magnetic fields. Subjected to a magnetic field, each type of magnetic nucleus resonates at a characteristic frequency, its resonance frequency. Nuclei will derivate from this resonance frequency, depending on the other nuclei it is bound to. This derivation is known as chemical shift and is typically recorded relative to the resonance frequency in parts per million (ppm). Depending on the chemical compound's structure, the resonance of a nucleus can split further into sets of resonances (figure 1), so-called splitting patterns. The resonance frequencies of a chemical compound, their chemical shift, and its resonance splitting patterns are highly indicative of a compound's chemical structure, making NMR spectroscopy one of the most valuable and most used tools in organic chemistry structure elucidation and validation.

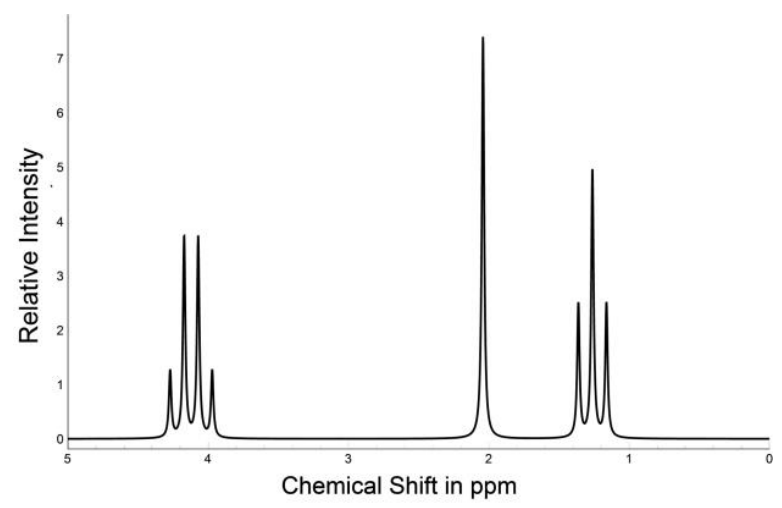

Figure 1: The hydrogen-1 NMR spectrum of ethyl acetate, with the signals at $4.1 \mathrm{ppm}$ and $1.2 \mathrm{ppm}$ split into quadruplet and triplet patterns, respectively.

As a simple analogy, a chemical compound can be thought of as a guitar string, which, by itself, is silent. Only when this string is fixed onto a guitar and plucked (analogous to subjecting a chemical to a strong magnetic field and exciting it with a radio pulse) a signal is emitted. In the case of the guitar string, this signal is a mechanical wave. In NMR spectroscopy an electromagnetic signal, also known as free induction decay, or FID, is recorded (figure 2). The FID is Fourier transformed and plotted as an NMR spectrum. 


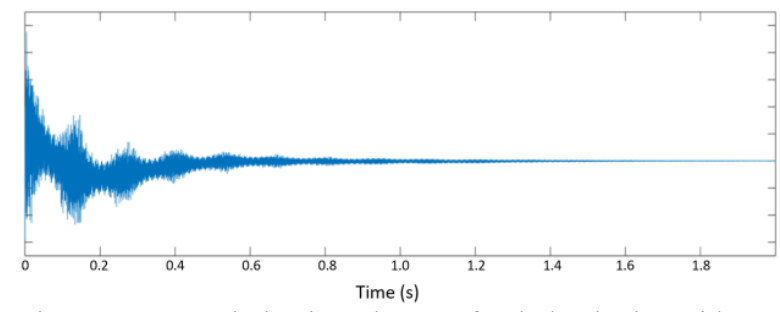

Figure 2: Free induction decay of ethylmalonic acid. Displayed using DOSYToolbox [7]. Data taken from [8].

\subsection{NMR sonification in science and art}

The chemical shifts in an NMR spectrum are conventionally displayed in parts per million but can be converted to frequencies values using (1), where $f$ is the chemical shift in hertz, $\delta$ the chemical shift in parts per million, $\gamma$ is the gyromagnetic ratio of the examined nuclei and $B_{0}$ is the strength of the external magnetic field.

$$
f=\delta \gamma B_{0}
$$

A feature of NMR spectra is that chemical shifts of a great number of different types of nuclei tend to lie in the range of zero to 20000 hertz, making NMR data an ideal candidate for audification. The audification of NMR data was sporadically used in analytical laboratories in the 1970s, as listening to the reference sample's pitch before an experiment was a fast way to check that the NMR machine was calibrated correctly [9]. As computing power increased, this tuning process was relegated to computer algorithms and the sound modules were eventually removed. In 2015, a program that sonified NMR data for analysis purposes was released [10], and its efficacy evaluated using simple NMR spectra.

The use of NMR data in an art-science context has only recently been explored, with the incorporation of audified NMR data into electroacoustic music compositions [11][12]. It has been shown that NMR sonification is not only a source of new musical timbres, but it can be used as an auditory indicator of inter-molecular interactions in virtual reality art installations [13]. The use of hydrogen-1 and carbon-13 NMR data for sonification has been examined elsewhere [11] and is well suited to display structural features of small molecules as sound. It is less suited for the display of structural features of molecules with only a small number of carbon or hydrogen atoms present, such as amino acids, organophosphates or nucleotides, and their macromolecular counterparts, such as proteins and DNA strands.

This paper expands the usage of NMR sonification by examining the sonification products of the NMR-active nuclei of three atoms commonly found in these organic compounds: nitrogen, phosphorous, and oxygen.

\section{NMR DATA SONIFICATION}

NMR data can be sonified using a variety of methodologies, including audification, additive synthesis, FM synthesis, or model-based synthesis. The sonification methodology employed here is based on the additive synthesis of NMR data (see figure 3).

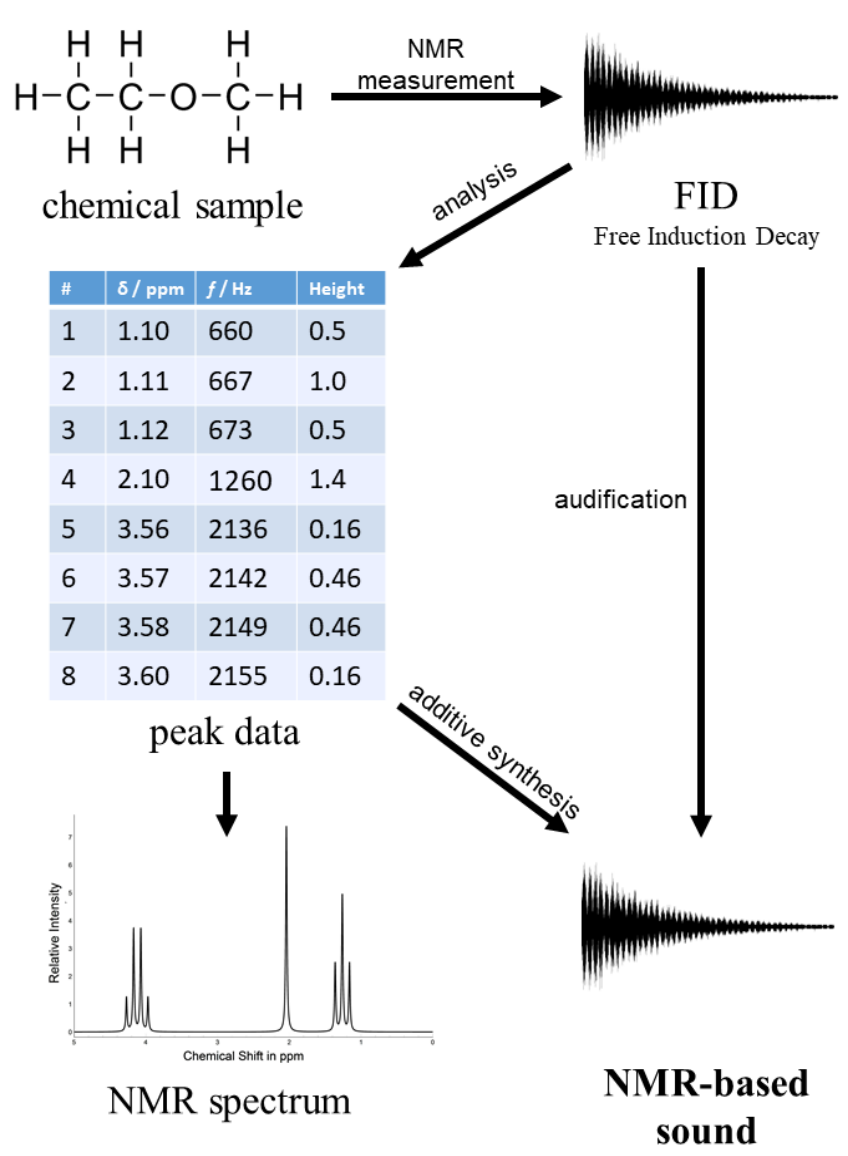

Figure 3: Methodology for the sonification of NMR data. Modified, based on [11].

\section{1. $15 \mathrm{~N}$ and $14 \mathrm{~N}$ NMR}

Nitrogen, together with carbon, hydrogen, oxygen, and phosphorous, is one of the most commonly found elements in organic matter. Nitrogen is a core component of nucleic acids and amino acids and macromolecular structures such as DNA, RNA, and proteins. Two different isotopes, nitrogen14, and nitrogen-15, are used in NMR spectroscopy. Unlike nitrogen-15, nitrogen-14 is a quadrupolar nucleus. Subjected to a magnetic field, a quadrupolar nuclei does not split into two magnetic orientations, but more. A nitrogen-14 nucleus has three possible orientations in a magnetic field. This means that instead of a single signal peak, nitrogen-14 will split into at least two signals. In $15 \mathrm{~N}$ and $14 \mathrm{~N}$ NMR, most signals lie in the range of zero to eight $\mathrm{kHz}$ for amines and amides and $10-25 \mathrm{kHz}$ for aromatic rings. The decay time of each nucleus ranges from 0.1 seconds to 3 seconds depending on its bonding partners, with tertiary nitrogen (that is, nitrogen bound to only carbon atoms) generally having longer decay times [14]. Nitrogen atoms tend to be less common in organic molecules compared to hydrogen or carbon. This means that $15 \mathrm{~N}$ NMR spectra of small molecules, such as amino acids, often only contain one or two nitrogen signals (figure 4). As the nitrogen quantity for small molecules is low, $15 \mathrm{~N}$ NMR can be used for the analysis and structure validation of macromolecules, such as DNA or proteins (figure 5), by comparing measured $15 \mathrm{~N}$ NMR spectra to computer predictions. 


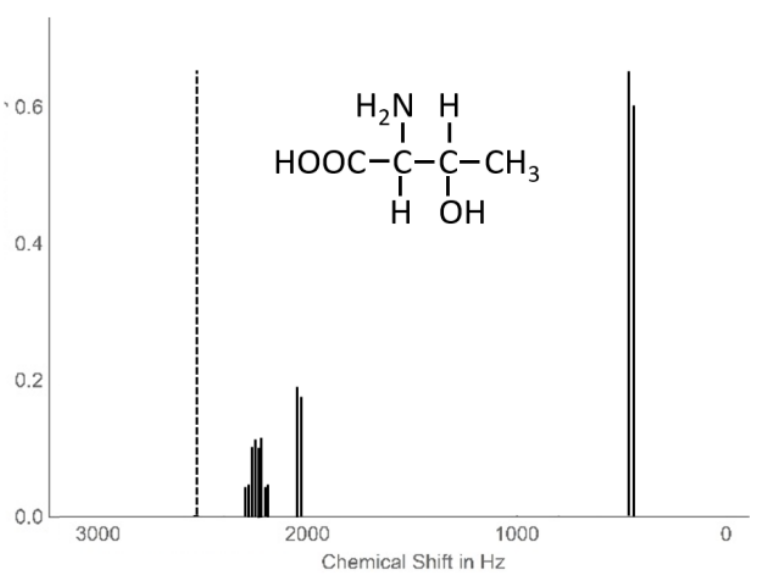

Figure 4: Comparison of NMR spectra of hydrogen-1 (continuous lines) and nitrogen-15 nuclei (dashed line) of L-allothreonine. The $1 \mathrm{H}$ NMR contains 3 frequency clusters with a total of 12 signals, whereas the $15 \mathrm{~N}$ NMR spectrum contains only one signal. Data taken from [15].

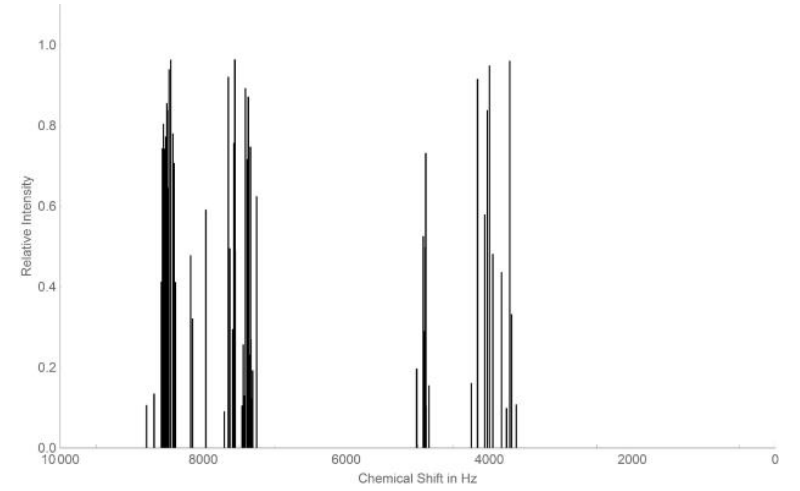

Figure 5: $15 \mathrm{~N}$ NMR of an RNA segment of a leaddependent ribozyme. Data taken from [16]. Sound example accessible via [17].

Sonification results of DNA bases contain a mix of high and mid-frequency content. Adenine, Guanine, and Cytosine contain an amine group resulting in a sharp triplet peak around 3 to $4 \mathrm{kHz}$ when measured under a magnetic field of 11.7 Tesla, a magnetic field strength commonly used for NMR analysis. All DNA bases exhibit signals around 7 to 10 $\mathrm{kHz}$ due to their pyrimidine-type structural features, with Adenine and Guanine exhibiting additional resonances around $6 \mathrm{kHz}$. Sonification results of DNA bases contain a mix of high and mid-frequency content. Adenine, Guanine, and Cytosine contain an amine group resulting in a sharp triplet peak around 3 to $4 \mathrm{kHz}$ when measured under a magnetic field of 11.7 Tesla, a magnetic field strength commonly used for NMR analysis. All DNA bases exhibit signals around 7 to $10 \mathrm{kHz}$ due to their pyrimidine-type structural features, with Adenine and Guanine exhibiting additional resonances around $6 \mathrm{kHz}$. Due to chemical factors, not all resonance can be resolved as sharp peaks, leading some peaks to sound closer to band-pass filtered noise. The final timbre of $15 \mathrm{~N}$ NMR sonification of DNA nucleotides is the sum of these noise bands, sharp peaks, and oscillating triplet patterns. DNA and RNA, being a sequence of a high number of DNA bases, exhibit similar resonance patterns as singular DNA nucleotides, however, each DNA nucleotide in

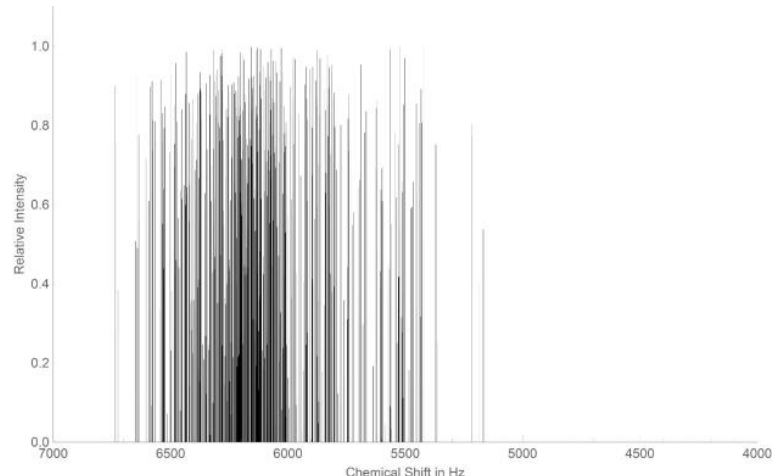

Figure 6: 15N NMR of an alkaline phosphatase protein. Data taken from [16]. Sound example accessible via [17].

a DNA sequence will have slight derivations of its resonance frequencies due to its chemical environment, leading to highly dense peak clusters (figure 5). 15N NMR spectra of proteins can be sonified, as well. In a protein, most nitrogen will be bound in the form of amides resonating in dense frequency clusters in a range of 5.5 to $6.5 \mathrm{kHz}$ (figure 6).

\subsection{P NMR}

The NMR active isotope of phosphorous is phosphorous- 31 . 31P NMR typically returns frequency peaks in the range of up to $1 \mathrm{kHz}$ for phosphates and up to $10 \mathrm{kHz}$ for phosphines and phosphine oxide with decay times of up to 230 milliseconds (figure 7). Phosphorous is incorporated into a small percentage of organic structures of which ADP, ATP and the sugar backbone of DNA and RNA are the most common. Due to their inharmonic low-frequency resonances, sonification products of 31P NMR resemble the sound of metallic bells. Unlike $15 \mathrm{~N}$ or $1 \mathrm{H}$ NMR spectra, features such as frequency clusters or sound wave pulsing of split peaks is less common in 31P NMR. Peak patterns of 31P NMR resemble more closely $13 \mathrm{C}$ NMR peak patterns, albeit at lower frequencies.

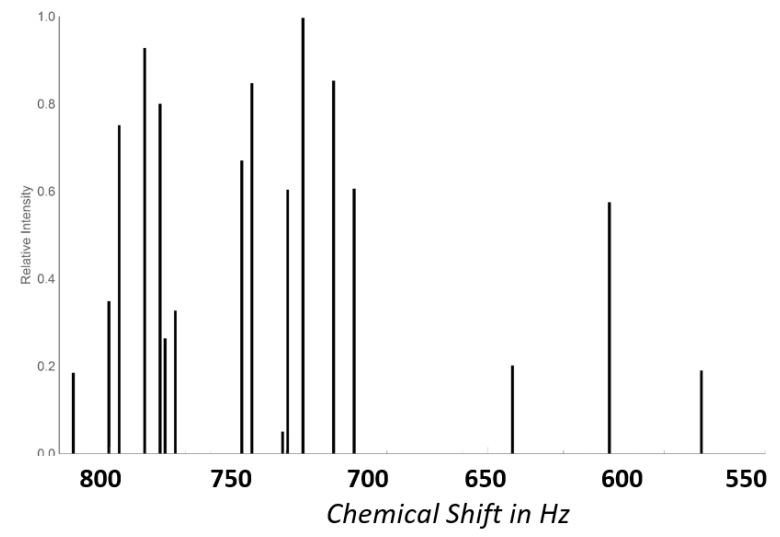

Figure 7: 31P NMR spectrum of an RNA strand of Bacillus subtilis. Data taken from [16]. Sound example accessible via [17].

\subsection{O NMR}

Like nitrogen-14, oxygen-17 is another quadrupolar nucleus with multiple resonance frequencies. Due to its nuclear composition, under a magnetic field, oxygen-17's spin states will occupy 6 distinct energy levels, leading to five 
resonances when examined via NMR spectroscopy. 170 NMR is used comparatively little due to the low natural abundance of oxygen-17 and its fast FID decay time of only 20 milliseconds, leading to broad NMR peaks. It is, however, useful for examining biochemical systems as well for the investigation of structural and dynamic features of organic and metal-organic compounds [18]. Sonification of 170 NMR data predominantly yields noise-based textures with broad peaks occupying frequency ranges of zero to $4 \mathrm{kHz}$ for esters and hydroxyl groups and between 13 and $15 \mathrm{kHz}$ for carboxylic functional groups.

\subsection{Data Sources}

The Biological Magnetic Resonance Data Bank [16] contains more than 9000 freely accessible $15 \mathrm{~N}$ spectra of proteins, peptides, DNA and RNA, as well as 125 phosphorous-31 datasets of DNA and RNA structures. The web database nmrshiftdb2 contains approximately 100 nitrogen- 15 and 50 phosphorous-31 spectra of small molecules [19]. The Wiley NMR collection contains 7500 spectra for nitrogen-15, 21000 datasets for phosphorous-31 and more than 5500 entries for oxygen-17 [20], however, these data are not freely available. No free prediction or simulation software for $14 \mathrm{~N}$, $15 \mathrm{~N}, 31 \mathrm{P}$ or $17 \mathrm{O}$ spectra exist, however, the necessary functionality is included in analysis software, such as ACD/Spectrus Processor [21] or NMRPredict [22], both offering free trial periods. $15 \mathrm{~N}$ NMR spectra for proteins can be predicted via [23].

\section{NMR SONIFICATION IN ACOUSMATIC MUSIC COMPOSITION}

Acousmatic music is a form of electroacoustic music that is presented using loudspeakers only. Acousmatic composition focuses on the gestural, textural, and spatial development of sound material [24], exploring sound creation and structuring processes beyond harmony, pitch, or meter [25][26].

A number of acousmatic compositions based on NMR data have been composed [12]. In these compositions, NMR data have been used for purely aesthetic purposes, to create and experiment with these data-based timbres and their impact on compositional procedures. NMR data have also been implemented as auditory information on molecular states for 3D molecular representations in virtual reality [13]. One of the biggest challenges for the deployment of NMR data sonification in music and sound art is the abstract nature of NMR data [13], making it hard for the audience to link the sounds heard to the underlying data. However, this link between data and sonification-based sound material is important for art and music-based works, as it has been noted for various art installations that the audience gains a deeper appreciation of the artwork when the link between data and audio-visual spectacle is clear [27]. In those cases, the audience can perceive science-based installations as "science and not art" [28] resulting in a shift in interaction and appreciation depending on the individual's preconceived notions of science [29]. Various pieces based on NMR-data have tried to supply the missing information in a variety of formats, including program notes, videos, workshops, talks, or interactive environments [12]. Another possibility, discussed in the following section, is the supply of necessary information via a hybrid drama of oral narration and acousmatic composition.

\subsection{Acousmatic storytelling, narration, and sonification}

Acousmatic storytelling is defined by Amelides as a combination of an acousmatic sound world with a voice narration [30]. The aim of music pieces based on acousmatic storytelling is not the exploration of sound transformations in space and time, as it is usual for acousmatic compositions, but the creation of a narrated sound world 'closer to human experience' [30], to contextualize and present cultural information and human experiences [30]. Examples of acousmatic storytelling are, H. Westernkamp's Kit's Beach Soundwalk or L. Ferrari's Far-West News. By combining abstract and referential sounds with a spoken narrative, Amelides argues, acousmatic storytelling can be utilized as a vehicle for historical presentation [30], as a way to transform private meaning into public meaning [31] or to present a personalised story.

The narrator in an acousmatic piece can take many forms, from passive omniscient observers to real or fictional characters, recounting (or trying to remember) first-hand experiences [32]. Voice narration arcs are often created from assembling pieces of recorded interviews and can combine multiple different points of view (e.g. the same moments recounted by a son and his mother) to form a full narrative. The reoccurrence of narrators can, in those cases, act as leitmotifs [33]. Other sound materials used in acousmatic storytelling are predominately field recordings, archival sound material and cultural sound icons (e.g. musical quotations of national anthems or the sound of church bells) [30], each being able to create their own independent nonvocal narratives [34].

The combination of voice narration, field recordings, abstract sound and their subsequent transformation in time creates a multilayered story. It falls to the listener to combine the parallel streams of narration to create a multifaceted representation of events described in the acousmatic piece. A process that engages the listener to interact with the acousmatic piece more closely. Amelides argues that as acousmatic storytelling is less abstract than pure acousmatic composition, a wider audience is reached [30].

Principles of acousmatic composition have been proposed as guidance to increase the communicative and aesthetic properties of sonification work [35][36]. Acousmatic storytelling, with its focus on the contextualisation of information, the creation of shared stories and the use of acousmatic sound material to support information delivery, can be a valuable contribution to the discourse on sonification aesthetics. On the Extinction of a Species, described in the following section, is an exploration of such a combination of acousmatic storytelling and sonification.

\subsection{On the Extinction of a Species}

On the Extinction of a Species [37] is a 23-minute, 7.1 channel, acousmatic composition that combines voice narration, field recordings, analog synthesis and sound material created from the sonification of NMR data. The structure of the piece follows events surrounding the demise and potential resurrection of the passenger pigeon (table 1 and figure 8).

The first section of the piece depicts a time where billions of pigeons roamed North America, using the sound of pigeons taking flight and pigeon calls as cultural sound icons complimented by a stable harmonic sound texture. 


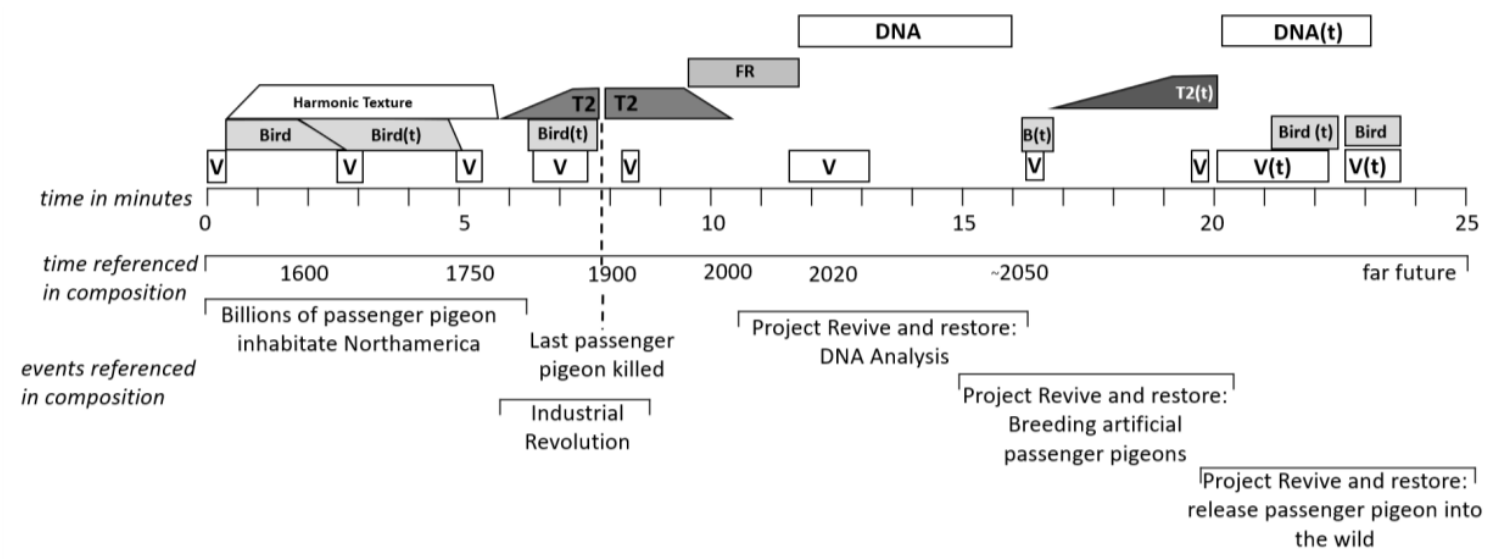

Figure 8: Structure of On the Extinction of a Species and its relation to referenced events. Sound material is abbreviated as follows: V - voice narration, Bird - sound of pigeon calls and birds taking flight, Harmonic Texture - Tonal music texture employed in section 1, T2 - noise-based sound texture, FR - field recording, DNA - sound material based on the sonification of DNA sequences of the passenger pigeon. Sound materials with the index $(\mathrm{t})$ are sounds that were transformed based on the sound source indicated, e.g. V(t) is sound material created by the transformation of sound type V. Graphic adopted from [12].

\begin{tabular}{|c|c|c|c|c|c|}
\hline Section & 1 & 2 & 3 & 4 & 5 \\
\hline Time in piece & $0-6 \min$ & $6-9 \min$ & $9-12$ min & $12-16 \min$ & $16-23 \mathrm{~min}$ \\
\hline Time referenced & $1000-1800 \mathrm{AD}$ & $1800-1950 \mathrm{AD}$ & $1950 \mathrm{AD}-$ now & near future & far future \\
\hline $\begin{array}{l}\text { Events } \\
\text { referenced }\end{array}$ & $\begin{array}{l}\text { Billions of } \\
\text { pigeons roaming } \\
\text { free in North } \\
\text { America }\end{array}$ & $\begin{array}{l}\text { The industrial } \\
\text { revolution and the } \\
\text { extermination of } \\
\text { the passenger } \\
\text { pigeon }\end{array}$ & $\begin{array}{c}\text { Ongoing } \\
\text { industrialisation } \\
\text { in a world } \\
\text { without the } \\
\text { passenger } \\
\text { pigeon }\end{array}$ & $\begin{array}{l}\text { Project 'Revive } \\
\text { and Restore': } \\
\text { analysis of the } \\
\text { pigeon's genome }\end{array}$ & $\begin{array}{l}\text { Digital resurrection } \\
\text { and digital } \\
\text { preservation of the } \\
\text { passenger pigeon }\end{array}$ \\
\hline $\begin{array}{l}\text { Narration } \\
\text { content }\end{array}$ & $\begin{array}{l}\text { AI introduces } \\
\text { itself and its } \\
\text { purpose }\end{array}$ & $\begin{array}{l}\text { AI describes the } \\
\text { extermination of } \\
\text { the passenger } \\
\text { pigeon }\end{array}$ & - & $\begin{array}{l}\text { AI proclaims its } \\
\text { desires to } \\
\text { resurrect the } \\
\text { pigeon, by } \\
\text { starting to } \\
\text { sequence the } \\
\text { pigeon's genome }\end{array}$ & $\begin{array}{l}\text { AI allocates more and } \\
\text { more resources to the } \\
\text { resurrection of the } \\
\text { pigeon, until its main } \\
\text { functions, including } \\
\text { its voice interface, } \\
\text { break down. }\end{array}$ \\
\hline Field recordings & - & - & City recordings & - & - \\
\hline $\begin{array}{l}\text { Cultural sound } \\
\text { icons }\end{array}$ & $\begin{array}{l}\text { Pigeon calls, } \\
\text { sounds of birds } \\
\text { taking flight, } \\
\text { sounds of } \\
\text { songbirds, with } \\
\text { more obvious } \\
\text { sound } \\
\text { transformations } \\
\text { towards the end of } \\
\text { the section } \\
\end{array}$ & $\begin{array}{l}\text { Processed bird } \\
\text { calls with strong } \\
\text { glitch-type } \\
\text { elements }\end{array}$ & $\begin{array}{l}\text { Rain hitting a } \\
\text { concrete floor as } \\
\text { well as the } \\
\text { sound of cars } \\
\text { and trains }\end{array}$ & - & $\begin{array}{l}\text { Transformations of } \\
\text { the AI's voice to bird } \\
\text { calls and reverse } \\
\text { transformations. }\end{array}$ \\
\hline $\begin{array}{l}\text { Abstract sound } \\
\text { material }\end{array}$ & $\begin{array}{l}\text { Harmonic sound } \\
\text { textures }\end{array}$ & $\begin{array}{l}\text { Noise-based } \\
\text { sound texture } \\
\text { derived from } \\
\text { trains and other } \\
\text { heavy machinery }\end{array}$ & $\begin{array}{c}\text { Heavily } \\
\text { processed bird } \\
\text { calls }\end{array}$ & $\begin{array}{c}\text { NMR data } \\
\text { sonification of } \\
\text { DNA sequences }\end{array}$ & $\begin{array}{l}\text { Transformed sound } \\
\text { material based on } \\
\text { DNA sequences }\end{array}$ \\
\hline
\end{tabular}

Table 1: Structure of On the Extinction of a Species, including the main sound elements used to create multilayered narrations.

Section 2 guides the listener through the industrial revolution and the extinction of the species in the late 18th century, using abstract noise-based sound textures reminiscent of an industrial landscape. Section 3 represents the 'now time', a bleak field recording of a noisy city soundscape. The fourth section of the piece envisions a future for the pigeon where its DNA is restored from preserved samples using genome sequencing, inspired by the real-world endeavors of 'Revive and Restore' [38]. The fifth section sees the story to its conclusion re-introducing and transforming sound material from the previous sections.

The piece is narrated by a fictional character, an artificial intelligence which is tasked with the retrieval, storage, and presentation of all data relating to extinct species. It addresses the audience directly and recounts the life of the passenger pigeon accompanied by the sound material previously described. In section 4, a key section of the piece, the AI decides to sequence the genome of the passenger pigeon from incomplete DNA data to create a virtual 
passenger pigeon, alive in digital eternity. Inspired by the project 'Revive and Restore', the AI musically 'processes' sequences of DNA strands to complete the analysis of the passenger pigeon's genome. The section is an homage to Hayashi and Munakata's sonification experiments in which DNA bases were assigned midi notes to find patterns in DNA sequences [39]. However, in the piece, DNA bases are not assigned to musical notes but are represented by the sound based on the sonification of NMR data of DNA nucleotides. The voice narration links the sounds heard to their data origin, by calling out the name of each DNA nucleotide when its NMR-based sound is heard for the first time. Using voice narration, this section introduces data as part of its narrative arc. Section 5 continues to present DNA-based sound material and voice narration as main driving forces of the composition, however, both voice and sonification-based sound materials are being heavily transformed approaching the conclusion of the piece. The voice narration becomes erratic and the voice itself sporadically transforms into bird song. The sonified DNA sequences jump erratically in pitch, playback speed, and continuity. Using these sound transformations, this section aims to break down the clear distinction of voice narration and acousmatic sound world, merging both to symbolize the breakdown of the AI narrator.

During the composition of the piece, a compositional conflict arose from the divergence of the story told by the narrator and the "data story" of NMR sonification, the data story being the influence of the nucleotide's structure on the sound characteristics of the NMR-based sound. As NMR sonification is not explained as part of the narration, the audience has no way of knowing if and what sonification methodologies have been employed to produce these sounds, reducing the merit of NMR-based sounds in this context to their aesthetic features. With On the Extinction of a Species' focus on telling the story of the demise of passenger pigeon, the data story inherent to NMR sonification had to be omitted.

\section{CONCLUSION}

A methodology for the audification of $14 \mathrm{~N}, 15 \mathrm{~N}, 17 \mathrm{O}$ and 31P NMR data is presented and possible sonification products of DNA, RNA and protein sequences are characterized. The combined efficacy of acousmatic storytelling and NMR sonification for the presentation of data as part of a fictional story was explored using the acousmatic piece On the Extinction of a Species. By means of a spoken narrative, field recordings, cultural sounds, abstract and sonification-based sounds, a multilayered narrative was created.

On the Extinction of a Species is only an initial exploration in the combination of sonification and acousmatic storytelling and proposed future work includes the investigation of acousmatic storytelling in a more sonification-focused context, using data stories as a focal point for voice narration and the design of the acousmatic sound world.

\section{REFERENCES}

[1] R. Herrmann, and C. Onkelinx, "Quantities And Units In Clinical Chemistry: Nebulizer And Flame Properties In Flame Emission And Absorption Spectrometry (Recommendations 1986)", Pure And Applied Chemistry, 58.12, 1986, pp. 1737-1742.

[2] S. V. Pereverzev, A. Loshak, S. Backhaus, J. C. Davis, and R. E. Packard, "Quantum Oscillations Between Two Weakly Coupled Reservoirs Of Superfluid 3He", Nature, 388.6641, 1997, pp. 449-451.

[3] E. Hill, J. Cherson, S. Goldfarb, and J. A. Paradiso, "Atlas data sonification: a new interface for musical expression and public interaction", 38th International Conference on High Energy Physics, 2016, pp. 1-3.

[4] S. Alexjander and D. Deamer, "The Infrared Frequencies Of DNA Bases: Science And Art", IEEE Engineering In Medicine And Biology Magazine, 18.2, 1999, pp. 74-79.

[5] T. Delatour, "Molecular Music: The Acoustic Conversion Of Molecular Vibrational Spectra", Computer Music Journal, 24, 2000, pp. 48-68.

[6] T. Delatour, "Molecular Songs", in Molecular Aesthetics, 1st edn (Karlsruhe: MIT - Press, 2013), pp. $293-311$.

[7] M. Nilsson, "The DOSY Toolbox: A new tool for processing PFG NMR diffusion data," Journal of Magnetic Resonance, 200, pp. 26-302, 2009.

[8] D. S. Wishart, T. Jewison, A. C. Guo, M. Wilson, and C. Knox, "HMDB 3.0 - The Human Metabolome Database in 2013," Nucleic Acids Res., vol. 1, p. 41, 2013.

[9] http://www.chemie.uni-erlangen.de/bauer/music4.html [Accessed 12 August 2018].

[10] J. W. Newbold, A. Hunt, and J. Brereton, "Chemical spectral analysis through sonification", The 21th International Conference on Auditory Display, 2015, pp. $329-330$.

[11] F. Morawitz, "Molecular Sonification Of Nuclear Magnetic Resonance Data As A Novel Tool For Sound Creation", Proceedings Of The International Computer Music Conference 2016, 2016, pp. 6-11.

[12] F. Morawitz, "Portfolio of Compositions", PhD Thesis, University of Manchester, 2019.

[13] F. Morawitz, "An Art-Science Case Study On Sonification And Sound Design In Virtual Reality", 2018 IEEE 4th VR Workshop On Sonic Interactions For Virtual Environments (SIVE), 1, 2018.

[14] A. Wei, M. K. Raymond, and John D. Roberts, "5N Nuclear Magnetic Resonance Spectroscopy. Changes in Nuclear Overhauser Effects and T1 with Viscosity", $J$. Am. Chem. Soc., 119, 1997, pp. 2915-2920.

[15] https://www.chemicalbook.com/SpectrumEN_144-989_1HNMR.htm [Accessed 29 March 2019].

[16] http://www.bmrb.wisc.edu/search/query_grid/NMR_para m_grid.html [Accessed 29 March 2019].

[17] Sound material can be accessed for review purposes on https://www.dropbox.com/sh/ogr3019e3a42e5s/AACCvy 4ORcFWVFHR-ZLxr511a?dl=0

[18] I. P. Gerothanassis "Oxygen-17 NMR spectroscopy: Basic principles and applications", Progress in Nuclear Magnetic Resonance Spectroscopy", 56.2, 2010, pp. 95197.

[19] http://nmrshiftdb.nmr.uni-koeln.de [Accessed 29 March 2019].

[20] https://sciencesolutions.wiley.com/solutions/wileyspectra-lab/nmr [Accessed 29 March 2019]. 
[21] https://webstore.acdlabs.com/software-solutions/acdspectrus-processor [Accessed 29 March 2019].

[22] http://mestrelab.com/software/mnova/nmr-predict/ [Accessed 29 March 2019].

[23] http://www.shiftx2.ca [Accessed 29 March 2019].

[24] D. Smalley, "Spectromorphology: Explaining SoundShapes", Organised Sound, 2, 1997, pp. 107-126.

[25] E. Varese and C. Wen-chung, "The Liberation of Sound", Perspectives of New Music, 5, 1, 1966, pp. 1119 .

[26] T. Wishart, On Sonic Arts, Routledge, 1996.

[27] D. Glowacki, P. Tew, J. Hyde, L. Kriefman, T. Mitchell, J. Price, and S. McIntosh-Smith, "Using Human Energy Fields to Sculpt Real-Time Molecular Dynamics", Molecular Aesthetics, 1.4, 2013, pp. 246 - 257; here, 249

[28] A. Vandso, "Listening To The World", Soundeffects, 1.1 2011, pp. 67-81.

[29] S. Emmerson, Living Electronic Music, Aldershot: Ashgate, 2007, pp. 35-57; here, 39.

[30] P. Amelides, "Acousmatic Storytelling", Organised Sound, 21.3, 2016, pp. 213-221.

[31] M. Jackson, The Politics of Storytelling: Violence, Transgression and Intersubjectivity. Tusculanum Press, 2002.

[32] W. C. Booth, The Rhetoric of Fiction, University of Chicago Press, 1961.

[33] J. Young, "Figures of Speech Oral History as an Agent of Form in Electroacoustic Music", Leonard music journal, 28, 2018, pp. 88-94.

[34] J. Andean, "Narrative modes in acousmatic music" Organised Sound, 21.3, 2016, pp. 192-203.

[35] P. Vickers, B. Hogg, "Sonification Abstraite/Sonificiation Concrete: An aesthetic perspective space for classifying auditory displays in the ars musica domain", Proceedings of the 12th International Conference on Auditory Display, 2006.

[36] F. Grond and J. Berger, "Parameter Mapping Sonification" in The Sonification Handbook, Logis Verlag, 2011.

[37] https://soundcloud.com/falk-morawitz/on-the-extinctionof-a-species-stereo-version [Accessed 29 March 2019].

[38] "About The Passenger Pigeon", Revive \& Restore $<\mathrm{http}$ ///reviverestore.org/about-the-passenger-pigeon/> [Accessed 15 January 2018]

[39] H. Kenshi, and N. Munakata, "Basically Musical", Nature, 310, 1984, p. 96. 